\title{
Produção X Clínica: Ação Humanizada Entre Colaboradores de uma Unidade de Nutrição Hospitalar e Pacientes Internados em um Hospital Público de Grande Porte
}

\author{
Jorge, Andréa Luiza; Carvalho, Juliana Toledo P. de; Fernandes, Renata; Teixeira, \\ Claudia de Fátima G.; Evazian, Denise \\ Instituto Central - HCFMUSP — andrea.jorge@hc.fm.usp.br
}

Introdução: para o indivíduo hospitalizado a alimentação supre necessidades básicas de manutenção e de recuperação da saúde, mas também deve propiciar conforto, bem estar físico e mental. Geralmente a baixa aceitação alimentar ocorre devido a: própria doença, falta de apetite, alterações do paladar, mudança de hábitos e insatisfação com as preparações, com o ambiente hospitalar e com o tipo de atendimento prestado. Ações humanizadas devem ser realizadas pela unidade de nutrição hospitalar para aprimoramento da ambiência, do acolhimento a pacientes e da gestão participativa das equipes de trabalho. Objetivos: Desenvolver projeto de visitas de integração entre colaboradores de produção e clínica da unidade de nutrição para aprimorar o atendimento a pacientes hospitalizados. Métodos: o projeto foi realizado em uma Unidade de Nutrição e Dietética hospitalar pública em 2013. Foram definidos como participantes os colaboradores de produção e clínica, com visitas aos pacientes no momento da distribuição de refeições nas unidades de internação. Houve planejamento prévio com a participação de instrutores da visita (nutricionistas das unidades de internação) e participantes (colaboradores das áreas de produção de refeições- nutricionistas, cozinheiros, atendentes de nutrição, auxiliares de serviços gerais). Aplicou-se um roteiro padronizado de visitas: informações sobre as características da enfermaria, perfil de pacientes atendidos, tipos de dietas e diálogo com pacientes. ao final da visita, foi aplicado um questionário a todos os colaboradores, com perguntas: 1- avaliação da atividade (ruim, regular, boa, ótima) com a respectiva justificativa; 2- questão aberta sobre propostas para melhorar a aceitação dos pacientes. Resultados: Realizou-se 13 visitas, com duração média de 60 minutos. Houve a participação de 41 colaboradores (11 atendentes de nutrição, 4 auxiliares de serviço, 11 cozinheiros e 15 nutricionistas, sendo 5 da produção e 10 da clínica). como resultado, a atividade foi considerada ótima $(71,2 \%)$ e boa $(28,8 \%)$. Quanto às justificativas, os comentários resultaram em: 1- importância de conhecer a visão do paciente sobre a refeição oferecida; 2valorização contínua da integração entre equipes de produção e clínica; 3- melhoria da consciência e comprometimento para a qualidade do atendimento; 4- importância da comunicação entre nutricionistas e colaboradores para aprimorar conhecimentos. As propostas da equipe para melhorar a aceitação dos pacientes foram: diversificar o cardápio e o modo de preparo; desenvolver novas receitas; aprimorar pratos com diferentes tipos de molho, além da valorização das visitas e do pedido de que sejam realizadas com maior frequência. Conclusões: o projeto resultou em avaliação positiva entre todos os participantes da unidade de nutrição. a integração entre colaboradores da produção e da clínica possibilitou o aprimoramento de ações envolvidas na humanização do atendimento nutricional de pacientes.

Jorge, Andréa Luiza; Carvalho, Juliana Toledo P. de; Fernandes, Renata; Teixeira, Claudia de Fátima G.; Evazian, Denise. Produção X Clínica: Ação Humanizada Entre Colaboradores de uma Unidade de Nutrição Hospitalar e Pacientes Internados em um Hospital Público de Grande Porte. In: Anais do Congresso Internacional de Humanidades \& Humanização em Saúde [= Blucher Medical Proceedings, num.2, vol.1]. São Paulo: Editora Blucher, 2014. ISSN 2357-7282 DOI 10.5151/medpro-cihhs-10462 